\title{
Evaluation of using pediatric emergency rooms
}

\author{
(1) Yakup Cag, ${ }^{1}$ (1) Mustafa Ozcetin, ${ }^{2}$ () Abdurrahman Avar Ozdemir, ${ }^{3}$ () Hanim Elveren \\ ${ }^{1}$ Department of Pediatrics, University of Health Sciences, Dr. Lutfi Kirdar Kartal Training and Research Hospital, Istanbul, Turkey \\ ${ }^{2}$ Department of Pediatrics, Istanbul University Istanbul Faculty of Medicine, Istanbul, Turkey \\ ${ }^{3}$ Department of Pediatrics, Biruni University Istanbul Medicine Hospital, Istanbul, Turkey \\ ${ }^{4}$ Association of Istanbul Anatolia South Public Hospitals General Secretary, Istanbul, Turkey
}

\begin{abstract}
OBJECTIVE: The overload of pediatric emergency units around the world has become an increasing problem for patients and health care professionals alike. Researching the features of pediatric emergency services will provide the necessary information for creating an effective emergency medical system, increasing patient satisfaction, and reducing the treatment costs. In this study; we aimed to check the admissions in pediatric emergency rooms, evaluate the effectiveness of emergency service, and develop suitable strategies to increase the amount and quality of medical service given in pediatric emergency rooms.

METHODS: In this retrospective study, the records of 296,858 (51.2\% female, $48.8 \%$ male) patient admissions in the emergency rooms and 384,171 (46.3\% female, 53.7\% male) admissions in the outpatient clinics of eight hospitals between January 2015 and June 2015 were scanned. Out of these hospitals, two facilities were research and training hospitals.

RESULTS: The average age of patients who were admitted to the emergency room was $89.1( \pm 21.3)$ months and the average age of patients admitted to the outpatient clinics was $87.2( \pm 18.7)$ months. Upper respiratory tract infection was the most frequent (44.23\%) diagnosis in the emergency rooms and most of these infected patients (63.67\%) had been admitted to the two training and research hospitals that provide an advanced level of health care. Also, the patient requests for diagnosis were determined to be significantly high in emergency rooms.

CONCLUSION: Proper understanding of the scope of emergency services is very important in order to provide fast and effective healthcare to the patients who get admitted to emergency rooms and maintain appropriate and judicious use of the resources of emergency rooms.

Keywords: Non-urgent; overcrowding; pediatric emergency.

Cite this article as: Cag Y, Ozcetin M, Ozdemir AA, Elveren H. Evaluation of using pediatric emergency rooms. North Clin Istanb 2019;6(2):134-140.
\end{abstract}

T he emergency rooms (ER) and outpatient clinics (OC) of the hospitals are the areas where newly admitted patients are diagnosed and treated promptly. These areas are accepted as being the showcase of the hospitals; they are the "windows" of the hospitals that are accessible by the public [1]. The main goal in building a health service system is to categorize patients on an emergency and non-emergency basis and refer them accordingly either to the ER or to the OC. In a study conducted in the U.S.A., it was shown that individuals who did not have health insurance had very limited access to health care services; the same services became augmented after these individuals were covered under health insurance. This approach also decreased the rates of ER admissions significantly [2]. However, in Turkey, the rate of ER admissions did not decrease under the same approach, despite there being easier access to health care services as compared to services available earlier $[3,4]$.

Received: January 13, 2018 Accepted: March 18, 2018 Online: August 27, 2018

Correspondence: Dr. Mustafa OZCETIN. Istanbul Universitesi Istanbul Tip Fakultesi, Cocuk Sagligi ve Hastaliklari Anabilim Dali, Istanbul, Turkey.

Tel: +90 5327248939 e-mail: mozcetin@gmail.com

(c) Copyright 2019 by Istanbul Provincial Directorate of Health - Available online at www.northclinist.com 
Generally, the numbers of ER admissions are always higher than the number of $\mathrm{OC}$ admissions. Also, $25 \%-50 \%$ of hospitalized patients are admitted to the ER initially [1]. Today, the overload of emergency services in many countries is a very well-known and documented problem. The overload of emergency service causes fatigue and stress in health care professionals and dissatisfaction in patients. It also decreases the quality of the service provided [5]. In 2002, the American College of Emergency Physicians (ACEP) described the overcrowding of ERs as "the inability of the current emergency facilities to fulfill the basic needs of patients who admit to the ER."

The reasons that contribute to overcrowding are different in adult and pediatric ERs. Admissions to pediatric ERs very rarely result in hospitalization $[6,7]$. The most important reason contributing to the overload in pediatric ERs is the excessive number of patient admissions. As a result of this overload, the waiting period is prolonged, the duration of stay in the ER gets increased, and the treatment becomes more expensive. A former study from the U.S.A. showed that the cost of running the ER could be up to four times higher than that of the OC $[4,8]$.

Preventing needless occupation of the pediatric ERs will increase patient satisfaction and quality of services and will contribute to decreasing the treatment costs. The aim of this study is to determine whether or not the pediatric ERs and OCs are capable of delivering kind of care that is compatible with their purpose, and designing suitable strategies to help overcome problems related to patient overload.

\section{MATERIALS AND METHODS}

Between January 2015 and June 2015, a retrospective review of medical records of the eight hospitals that are connected to the province of Istanbul was performed. Clinical and demographic data were retrospectively collected from the patients' medical records. This study was approved by a local institutional review board (No: 35278018-770) and written informed consent was obtained from local government authorities.

Patients of widely varying ages (from 1 month to 16 years) were included in the study. Demographic variables, number and type of diagnostic tests performed, and follow-up results of the patients who were admitted to the ER and OC were examined and compared. The diagnoses were categorized according to the International Classification of Diseases-10 (ICD-10) diagnostic coding system. The patients who were admitted had one or more of the following conditions; upper respiratory tract infections (URTI) (rhinitis, sinusitis, pharyngitis, otitis, laryngitis, laryngotracheitis), trauma and burns (various injuries originating from accidents, falls from heights, physical assault and exposure to heat, radiation, electricity or chemicals in the dermic and hypodermic tissue), general physical examination without any pathologic findings and diagnoses, gastrointestinal system diseases (gastroesophageal reflux disease, gastritis, gastroenteritis, constipation, intussusception, appendicitis, perforation, and intestinal obstruction), non-specific pain symptoms (headache, abdominal pain, chest pain or extremity pain in which an etiological factor has not been determined), lower respiratory tract diseases (acute bronchi-

TABLE 1. Distribution of the cases admitted to the emergency room and outpatient clinics according to age and gender groups

\begin{tabular}{|c|c|c|c|c|c|c|c|c|}
\hline Ages (months) & \multicolumn{4}{|c|}{ Emergency room } & \multicolumn{4}{|c|}{ Outpatient clinics } \\
\hline $1-12$ & 2199 & 0.74 & 1946 & 0.66 & 7151 & 1.86 & 9145 & 2.38 \\
\hline $12-24$ & 15837 & 5.34 & 15524 & 5.23 & 18346 & 4.78 & 23128 & 6.02 \\
\hline $60-144$ & 59620 & 20.08 & 54475 & 18.35 & 71513 & 18.62 & 81652 & 21.25 \\
\hline$>144$ & 38443 & 12.95 & 37666 & 12.69 & 46274 & 12.06 & 46949 & 12.22 \\
\hline Total & 151956 & 51.19 & 144902 & 48.81 & 177762 & 46.27 & 206409 & 53.73 \\
\hline
\end{tabular}




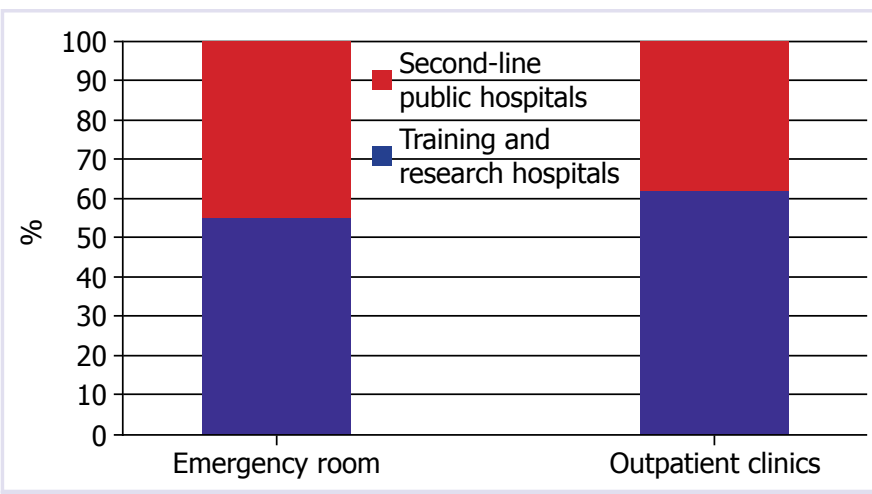

FIGURE 1. Distribution of patients in hospitals.

olitis, pneumonias, bronchiectasis, asthma, obstructive or restrictive lung diseases), urinary system diseases (urinary tract infections, urolithiasis, glomerular diseases), skin and dermal diseases (urticaria, erythema, dermatitis, eczema, bullous lesions), non- specific fever (fever in which an etiological factor has not been determined), ocular diseases (conjunctivitis, blepharitis, ocular extraneous body), hematologic diseases (anemias, coagulation disorders, immunodeficiency), and nervous system diseases (meningitis, encephalitis, neuropathy, convulsions, muscle diseases, cerebrovascular events).

The software program SPSS ver. 15.0 (Statistical Package for Social Sciences) for Windows was used in the research for statistical analysis and the value of $\mathrm{p}<0.05$ was considered significant.

\section{RESULTS}

Two of the eight hospitals included in the study were training and research hospitals and six of them were second-line public hospitals. A total of 296,858 (51.19\% female, $48.81 \%$ male) patients were admitted to the ER
(Group 1) and 384,171 (46.27\% female, 53.73\% male) patients were admitted to the OC (Group 2) from January 2015 to June 2015. Almost all the 269,852 (90.90\%) patients who were admitted to the ER were categorized into the diagnosis group. The "other" group (patients who very rare diseases which could not be further grouped in diagnosis groups) consisted of 27,006 (9.10\%) patients. OC patients who were part of the "other" group numbered 48,966 (12.75\%).

The average age of patients included in the study was $89.1( \pm 21.3)$ months in patients admitted to the ER while it was $87.2( \pm 18.7)$ months in patients admitted to the OC. The categorization of diagnosis groups in Group 1 and Group 2 are shown in Table 1. Female admissions to ER and male admissions to the OC was found significantly high $(p<0.05)$. A total of $55.14 \%$ of admissions to ER and $61.74 \%$ of admissions to OC were detected in training and research hospitals (Fig. 1). In Group 1, URTI $(44.22 \%)$ and trauma (14.48\%) were the most common diagnoses (Fig. 2$)(p<0.05)$. The relationship of patients with the diagnosis and age groups is seen in Table 2. A total of $63.67 \%$ of URTI patients were admitted to the ERs of training and research hospitals (Table 3). In Group 2, URTI $(22.41 \%)$ and general physical examination $(21.67 \%$ ) were the most common diagnoses (Fig. 3) $(\mathrm{p}<0.05)$ (Table 4). Further diagnostic tests were required for $49.43 \%(146,745)$ of the $296,858 \mathrm{ER}$ admissions and for $42.03 \%(161,469)$ of the 384,171 OC admissions. It was determined that more tests were required for ER admissions than for OC admissions and this difference was statistically significant $(\mathrm{p}<0.05)$ (Fig. 4).

\section{DISCUSSION}

This study showed that the most common reason for

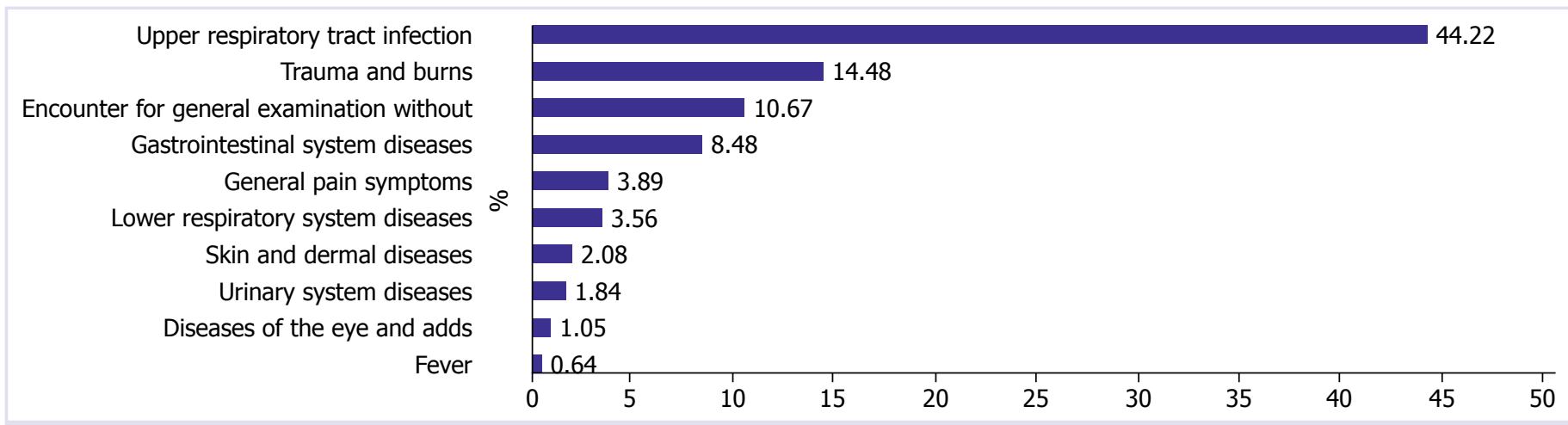

FIGURE 2. Prevalent diagnoses in the emergency room. 
TABLE2. Age distribution of the children according to prevalent diagnoses in the emergency room

\begin{tabular}{|c|c|c|c|c|c|c|c|c|c|c|c|c|}
\hline & \multicolumn{12}{|c|}{ Age (months) } \\
\hline & \multicolumn{2}{|c|}{$1-12$} & \multicolumn{2}{|c|}{$12-24$} & \multicolumn{2}{|c|}{$24-60$} & \multicolumn{2}{|c|}{$60-144$} & \multicolumn{2}{|c|}{$>144$} & \multicolumn{2}{|c|}{ Total } \\
\hline & $\mathrm{n}$ & $\%$ & $\mathrm{n}$ & $\%$ & $\mathrm{n}$ & $\%$ & $\mathrm{n}$ & $\%$ & $\mathrm{n}$ & $\%$ & $\mathrm{n}$ & $\%$ \\
\hline Upper respiratory tract infections & 1427 & 1.09 & 13559 & 10.33 & 32079 & 24.44 & 52092 & 39.68 & 32108 & 24.46 & 131265 & 100 \\
\hline Trauma and burns & 655 & 1.52 & 4162 & 9.68 & 9582 & 22.30 & 17264 & 40.18 & 11308 & 26.32 & 42971 & 100 \\
\hline General physical examination & & & & & & & & & & & & \\
\hline without complaint & 446 & 1.41 & 2686 & 8.48 & 8705 & 27.47 & 11338 & 35.78 & 8514 & 26.87 & 31689 & 100 \\
\hline Gastrointestinal system diseases & 338 & 1.34 & 2894 & 11.50 & 5827 & 23.16 & 9812 & 38.99 & 6294 & 25.01 & 25165 & 100 \\
\hline General pain symptoms & 142 & 1.23 & 1240 & 10.73 & 2734 & 23.65 & 4332 & 37.47 & 3112 & 26.92 & 11560 & 100 \\
\hline Lower respiratory systems diseases & 108 & 1.02 & 965 & 9.13 & 2438 & 23.07 & 4152 & 39.29 & 2905 & 27.49 & 10568 & 100 \\
\hline Skin and dermal diseases & 76 & 1.23 & 770 & 12.48 & 1338 & 21.69 & 2422 & 39.26 & 1563 & 25.34 & 6169 & 100 \\
\hline Urinary system diseases & 65 & 1.19 & 640 & 11.72 & 1173 & 21.49 & 2247 & 41.16 & 1334 & 24.44 & 5459 & 100 \\
\hline Ocular diseases & 48 & 1.55 & 432 & 13.92 & 755 & 24.32 & 1220 & 39.30 & 649 & 20.91 & 3104 & 100 \\
\hline Fever & 16 & 0.84 & 156 & 8.20 & 478 & 25.13 & 710 & 37.33 & 542 & 28.50 & 1902 & 100 \\
\hline
\end{tabular}

TABLE 3. Distribution of the most frequent diagnoses in hospitals

\begin{tabular}{|c|c|c|c|c|c|}
\hline & \multicolumn{2}{|c|}{ Training and research hospitals } & \multicolumn{2}{|c|}{ Second-line public hospitals } & \multirow{2}{*}{$\frac{\text { Total }}{\mathrm{n}}$} \\
\hline & $\mathrm{n}$ & $\%$ & $\mathrm{n}$ & $\%$ & \\
\hline Upper respiratory tract infections & 83578 & 63.67 & 47687 & 36.33 & 131265 \\
\hline Trauma and burns & 19526 & 45.44 & 23445 & 54.56 & 42971 \\
\hline General physical examination without complaint & 10600 & 33.45 & 21089 & 66.55 & 31689 \\
\hline Gastrointestinal system diseases & 15094 & 59.98 & 10071 & 40.02 & 25165 \\
\hline General pain symptoms & 6957 & 60.18 & 4603 & 39.82 & 11560 \\
\hline
\end{tabular}

Upper respiratory tract infection

Encounter for general examination without

Lower respiratory system diseases

Urinary system diseases

Gastrointestinal system diseases

Trauma burns and surgical diseases

Hematolıgic diseases

Skin and dermal diseases

General pain symptoms

Nervous system diseases

Diseases of the eye and adds

Fever

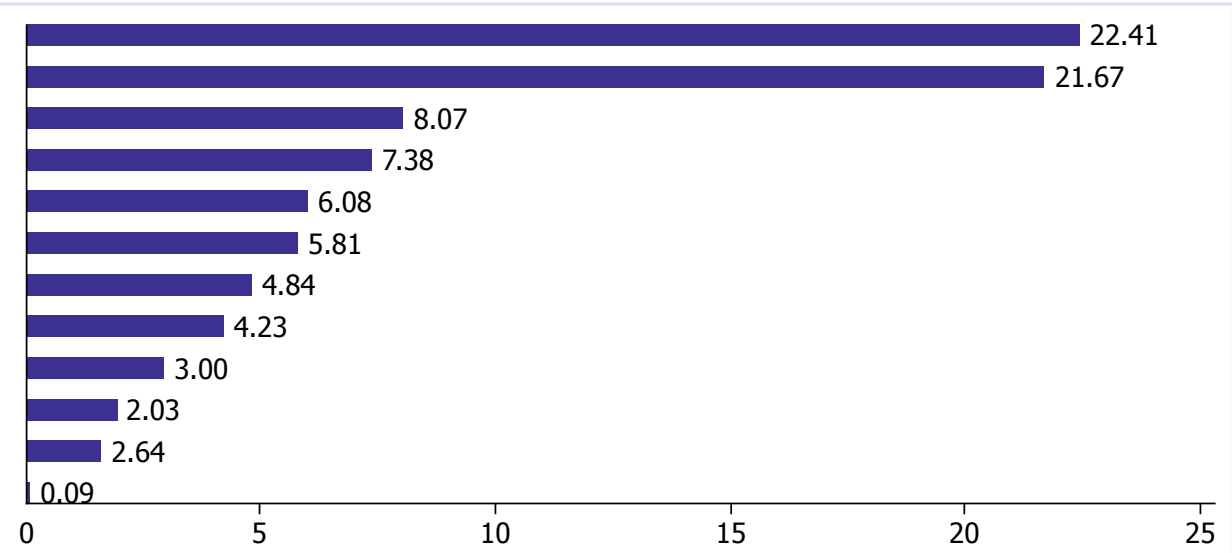

FIGURE 3. Prevalent diagnoses in outpatient clinics. 
TABLE 4. Age distribution of children according to the prevalent diagnoses in outpatient clinics

\begin{tabular}{|c|c|c|c|c|c|c|c|c|c|c|c|c|}
\hline & \multicolumn{12}{|c|}{ Age (months) } \\
\hline & \multicolumn{2}{|c|}{$1-12$} & \multicolumn{2}{|c|}{$12-24$} & \multicolumn{2}{|c|}{$24-60$} & \multicolumn{2}{|c|}{$60-144$} & \multicolumn{2}{|c|}{$>144$} & \multicolumn{2}{|c|}{ Total } \\
\hline Upper respiratory tract infections & 2840 & 3.30 & 9274 & 10.77 & 21645 & 25.15 & 39025 & 45.34 & 13294 & 15.44 & 86078 & 100 \\
\hline Lower respiratory systems diseases & 1280 & 4.13 & 4748 & 15.32 & 8453 & 27.28 & 12395 & 40.00 & 4110 & 13.26 & 30986 & 100 \\
\hline Urinary system diseases & 580 & 2.05 & 2684 & 9.47 & 5066 & 17.88 & 14046 & 49.57 & 5960 & 21.03 & 28336 & 100 \\
\hline Gastrointestinal system diseases & 1254 & 5.37 & 3088 & 13.22 & 5539 & 23.71 & 8957 & 38.34 & 4526 & 19.37 & 23364 & 100 \\
\hline Trauma burns and surgicaldiseases & 467 & 2.09 & 2635 & 11.80 & 5051 & 22.61 & 7102 & 31.79 & 7082 & 31.71 & 22337 & 100 \\
\hline Hematologic diseases & 642 & 3.45 & 2864 & 15.39 & 4286 & 23.04 & 6836 & 36.74 & 3978 & 21.28 & 18606 & 100 \\
\hline Ocular diseases & 940 & 14.93 & 1029 & 16.34 & 982 & 15.59 & 2102 & 33.38 & 1245 & 19.77 & 6298 & 100 \\
\hline Fever & 36 & 10.03 & 89 & 24.79 & 110 & 30.64 & 98 & 27.30 & 26 & 7.24 & 359 & 100 \\
\hline
\end{tabular}

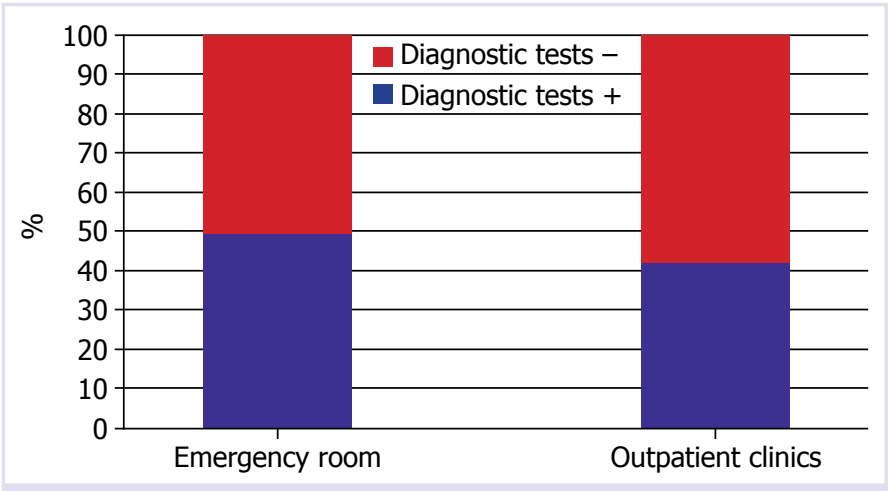

FIGURE 4. Rates of diagnostic tests required from patients admitted to emergency rooms and outpatient clinics.

pediatric ER and OC admissions in Istanbul was for URTI. Although not statistically significant, both ER and OC admissions preferred the two training and research hospitals when compared to the other six general state hospitals.

In a comprehensive study in the U.S.A., the average age of the children who admitted to the hospitals was determined as 6.9 years and it was reported that more than half of all applications were the children were aged $0-4$ years [9]. Compatible with this literature, the average age of admissions in both Group 1 and 2 in our study was found to be 7 years. In previous studies, the rate of admission of younger age groups was high $[10,11]$. In our study, the ER admission rate of children under 5 years was found at $35.96 \%$. Only $11.97 \%$ of patients admitted to ERs were under 2 years. At the same time, the age distribution of patients in OCs was also found similar to that in ERs. The variance in age distribution may be explained by the school attendance age since a school-going child will certainly be exposed to more infectious and traumatic agents than a child at home.

In $2005,65 \%$ of patients who applied to emergency services were composed of non-urgent cases and this rate has reached $70 \%$ today [12]. This finding should be enough to motivate the scientific community to think of new strategies for streamlining ER admissions.

When we evaluated patients according to their diagnosis, we detected that many conditions that could be treated in OCs and primary healthcare services were being attempted in emergency services. This indicates that patients prefer using emergency services instead of being examined in turn by doctors because of the easy and fast access to ERs verses having to wait for an appointment. In ER admissions, the diagnosis of URTI (44.22\%) and trauma $(14.48 \%)$ were the most common $[9,13]$. We determined that most of the patients who were diagnosed 
with URTI in emergency services were admitted in tertiary hospitals.

In a study carried out in the U.S.A., it was reported that respiratory tract infections were seen mostly in younger children while injuries were seen mostly in older children [9]. In our study, ERs were identified as the first point of diagnosis of URTI in all groups and the diagnosis of URTI was more common in ERs than in OCs. The most common diagnosis groups in the OCs were URTI and general examination, including complaints of Mongolian spot, teething, physiological developmental behaviors, and non-specific controls. While it is acceptable that general examination is one of the most common diagnoses in OC, it becomes a problem when it is one of the most common diagnoses in the ER.

Appropriate medical care in ERs in terms of cost and effectiveness is also important. The cost of patients getting admitted to ERs is much more than the cost of patients getting admitted to OCs [8]. As per the record of diagnostic tests in our study, we found that investigations were required in $49.43 \%$ of ER admissions and $42.03 \%$ of OC admissions. This may be because of an insufficient number of specialized health staff working in ERs or because of the tendency of the physicians to maximize time in order to examine more patients. One of the most important proven reasons for overload in ERs is the unnecessarily prolonged patient stay in the ER [14], and diagnostic tests combined with waiting time for results leads to exactly this situation. Additional diagnostic tests also increase treatment costs.

Qualified and functional health services will lead to more number of healthy individuals. Although the level of quality of health services varies from country to the country, the main target is to ultimately best protect the health of the patients. In recent years, it has become easier for people to access health services as a result of the increasing demand for quality health services and changing health policies. Due to these policies, patients should be able to reach a healthcare facility before the condition warrants emergency status. Thus, lower rates of ER admissions can be expected, however, our study has demonstrated that despite all new approaches and new policies, individuals still prefer ER admissions even for non-emergencies. The reasons underlying this condition should be evaluated meticulously in order to prevent this attitude.

In many countries including ours, the only unit that can provide health care services to children at all hours is the pediatric emergency service. Therefore, in some situations (weekends, holidays, after $5 \mathrm{pm}$, etc.) patients have no choice but to get admitted to the ER in order to receive healthcare. Further, inadequate number of pediatric ERs, inadequate number of beds in hospitals (or decreasing the number of beds for directory reasons), and inadequate number of trained and experienced staff such as physicians and nurses who can give emergency health care services are among the other important reasons for overload in the ER [15]. On the other hand, over-caring parents are another contributory factor in the overload of pediatric ER. Former studies have shown that mothers tend to consider their children to have more serious diseases than what is the actual condition [16].

Occupying the emergency services for non-emergency cases is a big problem in many countries including ours $[17,18]$. To counter this, there are some suggestions and applications present in ERs that facilitate effective care and better workflow. The most common ones are; fivestep triage system, emergency care applications started by the nurse at the first admission, fast maintenance, grouping of patients, and providing more trained and tolerant staff with improved clinical skills [19].

The overload of ERs can be decreased by strengthening the primary health care services, structuring the agenda of the referral chain, and by organizing OCs on duty for some hours out of the conventional working hours for a certain time period. Additionally, some public awareness that explains to the people when they should apply to ERs and where and when they should get the appropriate healthcare services can be telecast over mass media.

In conclusion, the proper use of ER can be summarized as an appropriate patient being present at the appropriate health care facility at the appropriate time. By this method, the real emergency patients who are arriving the ERs can receive medical care faster and more effectively and the sources of ER can be used properly. This problem cannot be solved on a personal level and definitely requires proper governmental intervention and organization of health care systems worldwide.

Acknowledgements: We thank clinical research development Istanbul Anatolian South Public Hospitals Association for access to medical records and editing this article.

Conflict of Interest: The authors declare no conflict of interest.

Financial Disclosure: The authors declared that this study has received no financial support. 
Authorship Contributions: Concept - MO; Design - YC; Supervision - AAO; Materials - YC; Data collection and/or processing - HE; Analysis and/or interpretation - YC; Writing - MO; Critical review - YC.

\section{REFERENCES}

1. Schneider SM, Gallery ME, Schafermeyer R, Zwemer FL. Emergency department crowding: a point in time. Ann Emerg Med 2003;42:16772. [CrossRef]

2. McWilliams JM, Meara E, Zaslavsky AM, Ayanian JZ. Use of health services by previously uninsured Medicare beneficiaries. N Engl J Med 2007;357:143-53. [CrossRef]

3. Mahsanlar Y, Parlak I, Yolcu S, Akay S, Demirtas Y, Eryigit V. Factors Affecting the Length of Stay of Patients in Emergency Department Observation Units at Teaching and Research Hospitals in Turkey. Turk J Emerg Med 2016;14:3-8. [CrossRef]

4. Galarraga JE, Pines JM. Costs of ED episodes of care in the United States. Am J Emerg Med 2016;34:357-65. [CrossRef]

5. Guttmann A, Schull MJ, Vermeulen MJ, Stukel TA. Association between waiting times and short term mortality and hospital admission after departure from emergency department: population based cohort study from Ontario, Canada. BMJ 2011;342:d2983. [CrossRef]

6. Stang AS, McGillivray D, Bhatt M, Colacone A, Soucy N, Léger R, et al. Markers of overcrowding in a pediatric emergency department. Acad Emerg Med 2010;17:151-6. [CrossRef]

7. Doan Q, Genuis ED, Yu A. Trends in use in a Canadian pediatric emergency department. CJEM 2014;16:405-10. [CrossRef]

8. Cremonesi P, Di Bella E, Montefiori M. Cost analysis of emergency department. J Prev Med Hyg 2010;51:157-63.

9. Merrill CT, Owens PL, Stocks C. Pediatric Emergency Department Visits in Community Hospitals from Selected States, 2005: Statistical Brief \#52. Available at: http://www.hcup-us.ahrq.gov/reports/statbriefs/sb52.pdf. Accessed Apr 2, 2019.
10. Derinöz O, Tunaoğlu FS. Usage of pediatric emergency department observation unit for children: observations in a university hospital. Turk Pediatri Ars 2007;42:61-4.

11. Pileggi C, Raffaele G, Angelillo IF. Paediatric utilization of an emergency department in Italy. Eur J Public Health 2006;16:565-9.

12. Erenler AK, Akbulut S, Guzel M, Cetinkaya H, Karaca A, Turkoz B, et al. Reasons for Overcrowding in the Emergency Department: Experiences and Suggestions of an Education and Research Hospital. Turk J Emerg Med 2016;14:59-63. [CrossRef]

13. Boran P, Tokuç G, Büyükkalfa DÇ, Taşkın B, Pişgin B. Evaluation of the Patients Admitted to the Pediatric Emergency Department. J Child 2008;8:114-6.

14. Singer AJ, Thode HC Jr, Viccellio P, Pines JM. The association between length of emergency department boarding and mortality. Acad Emerg Med 2011;18:1324-9. [CrossRef]

15. Hostetler MA, Mace S, Brown K, Finkler J, Hernandez D, Krug SE, et al; Subcommittee on Emergency Department Overcrowding and Children, Section of Pediatric Emergency Medicine, American College of Emergency Physicians. Emergency department overcrowding and children. Pediatr Emerg Care 2007;23:507-15. [CrossRef]

16. Doobinin KA, Heidt-Davis PE, Gross TK, Isaacman DJ. Nonurgent pediatric emergency department visits: Care-seeking behavior and parental knowledge of insurance. Pediatr Emerg Care 2003;19:10-4.

17. Harris L, Bombin M, Chi F, DeBortoli T, Long J. Use of the emergency room in Elliot Lake, a rural community of Northern Ontario, Canada. Rural Remote Health 2004;4:240.

18. Bektemür G, Osmanbeyoğlu N, Cander B. Emergency Department Care Survey. Eurasian J Emerg Med 2015;14:1-33. [CrossRef]

19. Barata I, Brown KM, Fitzmaurice L, Griffin ES, Snow SK; American Academy of Pediatrics Committee on Pediatric Emergency Medicine; American College of Emergency Physicians Pediatric Emergency Medicine Committee; Emergency Nurses Association Pediatric Committee. Best practices for improving flow and care of pediatric patients in the emergency department. Pediatrics 2015;135:e273-83. [CrossRef] 